\title{
La mejor forma de vida en el régimen político ideal de Aristóteles
}

\author{
The Best Form of Life in Aristotle's \\ Ideal Political Regime
}

\author{
Viviana SUÑOL \\ Universidad Nacional de La Plata, Argentina
}

Recibido: 14/03/2014

Aceptado: 04/09/2014

\section{Resumen}

La investigación sobre la felicidad y las formas de vida constituye el núcleo del pensamiento ético-político de Aristóteles. En Política VII 2-3, el Estagirita nos ofrece uno de los pasajes más ricos para el estudio de la discusión iniciada en el siglo $\mathrm{V}$ a. C. sobre los bíoi, al establecer un debate dialéctico entre los defensores de la vida política y la filosófica. En el marco de esa contraposición, en Pol. VII 3 (1325b14-31) asume una postura ciertamente ambigua al afirmar que la vida más elegible es la práctica y al proponer una definición de práxis que incluye como su forma superior la de carácter teórico. En la literatura actual no hay acuerdo respecto de la interpretación general del pasaje, ni siquiera sobre cuál es la forma de vida que Aristóteles defiende allí. También se discute la naturaleza de esta práxis teórica, a la cual algunos identifican plenamente con la filosofía y otros, con una mera actividad cultural. A pesar de la complejidad del texto y de las divergencias a las que su exégesis ha dado lugar, intentaremos determinar cuál es el ideal de vida del mejor régimen teniendo en cuenta las indicaciones tácitas y expresas que Aristóteles nos ofrece en la construcción de su programa político ideal. 
Palabras clave: Aristóteles, Contemplación, Ética, Filosofía, Formas de vida, Política, Régimen ideal.

\begin{abstract}
The investigation about happiness and forms of life is the core of the Aristotelian ethico-political thought. In Politics VII 2-3, he offers one of the richest passages for the study of the discussion that started in the fifth century B. C. about the ways of life, by the dialectical debate he establishes between the supporters of the political and the philosophical life. In the context of that debate, he assumes in Pol. VII 3 (1325b14-31) a position certainly ambiguous saying that the most eligible life is the practical one, at the time he proposes a definition of praxis that includes as its highest form the theoretical activity. In current academic literature there is no agreement about the general interpretation of the passage not even about the way of life Aristotle defends here. The interpreters also discuss the nature of this theoretical praxis, which some fully identify with philosophy and others, with a mere cultural activity. Despite the complexity of the text and the differences of its interpretations, we will try to determine which is the best form of life for living in the best regime, by considering the explicit and tacit indications that Aristotle offers us in the construction of his ideal political program.
\end{abstract}

Keywords: Aristotle, Contemplation, Ethics, Philosophy, Ways of Life, Politics, Ideal Regime.

\title{
Introducción
}

La discusión sobre la eudaimonía ${ }^{1}$, en particular, sobre las distintas formas de vida que permiten alcanzarla constituye el tema central del pensamiento

\footnotetext{
${ }^{1}$ Etimológicamente, la palabra eudaimonía refiere a la buena fortuna y, de manera secundaria, a la prosperidad material (s.v. LSJ). Como puede observarse en distintas obras del corpus y, en especial, al comienzo y al final de la Ética a Nicómaco, Aristóteles apunta a una definición más compleja que hace de ella el fin último de la vida (EN I 4 1095a14-18; X 6 1176a31-32, 1176b30-31). El sabio como eudaimonéstatos cuenta con el favor de los dioses (EN X 8 1179a29-32) y debe poseer, de manera moderada, recursos exteriores como condiciones necesarias de la eudaimonía (EN I 10 1101a15; X 8 1178b23-24, 33-35; 1179a8-16; Pol. VII 13 1331b41-1332a2). Aunque usualmente el término se traduce por "felicidad", no hay acuerdo en la literatura especializada. Así, por ejemplo, ACKRILL (1975: 349) prefiere hablar de "la mejor vida posible" (the best possible life), donde "mejor" no tiene un sentido estrictamente moral o bien CHARLES (1999: 205), quien traduce el término como "bien humano" (human good) o "bienestar" (human well-being). También hay quienes optan por mantener el vocablo en su original griego, p. ej.: SCOTT (1999: 225 n.1). Si bien es cierto que la definición española
} 
ético-político de Aristóteles. A pesar de la preeminencia que de manera indudable le reconoce a lo largo del corpus al ideal contemplativo, ${ }^{2}$ en los distintos pasajes en los que el Estagirita se ocupa de esta cuestión no deja en claro cuál es la relación entre los dos modos de vida que - siguiendo la tradición iniciada en el siglo $\mathrm{V}$ a. C. ${ }^{3}$ - considera como candidatos de la vida mejor, esto es, el

de 'felicidad' no se ajusta a la complejidad que este concepto tiene en Aristóteles (s.v. RAE), ningún otro término o expresión parece capaz de hacerlo, ya que el Estagirita le dedica buena parte de la $E N$ para esclarecer su significado, el cual es aún hoy objeto de discusión. Por esta razón, mantengo la traducción habitual teniendo en cuenta la complejidad que el propio Aristóteles le reconoce a la eudaimonía como concepto medular de su pensamiento ético-político. Sobre el inagotable e inabarcable debate académico entre quienes apoyándose en $E N$ I postulan una definición inclusiva de la eudaimonía y los defensores de una comprensión dominante expuesta en el último y las dificultades que cada una de ellas enfrenta, cfr. Lisi (2004a: 14-23) y DEPEW (1991: 360-361).

${ }^{2}$ En EN X 7-8 es donde Aristóteles más claramente destaca la supremacía de la actividad contemplativa (theoría). En este texto asume una postura claramente intelectualista y ello ha determinado la consideración que, de manera tradicional, se le ha dado - junto a su maestro- como uno de los defensores de la vida contemplativa (FESTUGIÈrE 1950: 18; JAEGER 2011: 484; BÉNATOUÏL y BONAZZI 2012: 4, 17). El reconocimiento de una forma secundaria de eudaimonía y, sobre todo, la alusión a los requerimientos de la existencia humana revelan que no propone un intelectualismo extremo (SUÑOL 2013: 21-22). En EN I 5 la superioridad de la vida contemplativa se desprende del rechazo expreso de la vida placentera y de la política, si bien otras alusiones menos directas también abonarían esta superioridad (EN I 7 1097a25-b2; 10 1100b19). Como veremos, la afirmación del bíos praktikós como bíos áristos en Pol. VII dado lugar a interpretaciones muy diversas, aunque parece difícil no vincular esta forma de vida a la actividad contemplativa. En $E E$ I 4-5 también recurre al esquema de los tres bioi y refiere a la superioridad de la contemplativa (EE I 7 1217a26-28, 39-40; VIII 3 1219b16-21) y en Protr. B 55-57 alude a la vida filosófica como la mejor y destaca su autonomía respecto de las restantes actividades.

${ }^{3}$ El debate sobre las formas de vida está estrechamente emparentado al surgimiento de la filosofía, a la vez, como disciplina y como forma de vida (HADOT 1998) y a los cambios sociales y políticos que Atenas, por entonces, experimentaba. A partir de Platón y, sobre todo, de Aristóteles el debate sobre los bíoi se planteó como conceptualmente inseparable de la discusión sobre la felicidad (eudaimonía), lo que no solo determinó que se convirtiera en tema central de la ética griega clásica, sino que su compresión estuviera subordinada a este tema, lo cual todavía hoy se observa en la literatura especializada (LISI 2004a: 23; SUÑOL 2013: 16-17). Aunque se desconoce cuándo comenzó la codificación de las formas de vida, en la República (581c) Platón distingue claramente tres clases de hombres: el que es aficionado al conocimiento (philósophon), el que lo es a las victorias (philónikon) y el que lo es de las posesiones (philokerdés). Esta distinción se desprende de la triple división del alma (Resp. 580d-e) y se corresponde, a su vez, con una jerarquía del placer (Resp. 583a-b) (JAEGER 2011: 476 n.17). A través de las célebres anécdotas biográficas de los primeros filósofos, Platón (Teeteto 174d) y Aristóteles (Pol. 6, EN 1141 b 2; EE 17; Metaf. I 1 981b23-25) remitieron el origen de la vida contemplativa a sus antepasados presocráticos y aunque pueda considéraselos como sus precursores, en realidad fue Platón quien definió, por primera vez, la filosofía como forma de vida, codificó los tres bíoi e hizo del bios theorétikós el ideal más elevado ligándolo a la felicidad. En suma, Platón le dio entidad filosófica al debate sobre las formas de vida. Aunque fue Aristóteles, quien transformó esta cuestión en el centro mismo de su pensamiento ético-político (Lisi 2004a: 11). Si bien se reconocían otras formas posibles de vida, el debate se centró en la contraposición entre el bios theoretikós y el bios praktikós, que, en términos generales, se corresponden con la vida filosófica y la política respectivamente. La relevancia de esta oposición en la historia del pensamiento occidental parece indiscutible, pues a través de sus múlti- 
contemplativo y el político. ${ }^{4}$ Tal es el caso de los célebres capítulos finales del último libro de la Ética a Nicómaco, en los que de manera paradigmática exalta el ideal contemplativo y en los que salvo la breve alusión a que el hombre contemplativo "en cuanto hombre y en cuanto convive con muchos elije actuar conforme a la virtud" (EN X 8 1178b5-7), no explica cómo se articula la eudaimonía primaria —originada en la práctica de la contemplación — con la secundaria, propia del ejercicio de las virtudes humanas. ${ }^{5}$ Tampoco en el preámbulo ético que precede al diseño del mejor régimen político en Política VII 1-3 — que es en donde con más detenimiento se ocupa del debate sobre los bíoi y de manera más clara se pronuncia sobre la vida más elegible (bion hairetótaton, Pol. 1325a17) ${ }^{6}$ - Aristóteles aclara en qué consiste concretamente la vida

ples variantes se prolonga desde la filosofía griega clásica hasta el pensamiento político contemporáneo. Respecto de su apropiación por Leo Strauss y Hannah Arendt, cfr. GreGORIO 2004.

${ }^{4}$ En las obras ético-políticas de Aristóteles pueden identificarse dos esquemas a través de los cuales se refiere a la cuestión de las formas de vida. Por un lado, el modelo tripartito de la vida placentera, la política y la contemplativa que aparece atestiguado en Protr. B 94, EE I 4-5 y en $E N$ I 5, que es heredero de la codificación platónica de los bioi. Por otro, la oposición binaria de la vida política versus la filosófica, a la cual apela en Pol. VII 1-3 y en EN X 7-8, que remite al debate de los siglos V y IV a. C. entre los defensores del ideal aristocrático de la tranquilidad y los sostenedores de la ética ateniense de la actividad y en el cual, el propio Estagirita participa. En ambos casos, la consideración de los bíoi está vinculada a la eudaimonía. Asimismo, Aristóteles reconoce la existencia de otras formas de vida que carecen de nobleza y, por ende, son ajenas al ideal eudaimonístico: son aquellas que se cultivan por necesidad, como es el caso de quienes se dedican a las artes vulgares, manuales o a los negocios ( $E E$ I 4 1215a26-32, EN I 5 1096a5).

${ }^{5}$ En este sentido, HEINAMAN (1988: 35), quien reconoce que la contemplación es la forma más alta de eudaimonía y que la acción moral es una clase secundaria, sostiene que no hay evidencia que pruebe que la perspectiva de la acción moral y de la contemplación sean condiciones necesarias una de la otra y que cada una cuente como eudaimonía solo si la otra está presente. A pesar de la superioridad de la contemplación, HeINAMAN (1988: 46) reconoce que ella no puede abarcar totalmente la vida de un ser humano y que es preciso determinar en cada caso cuál de las dos se ha de elegir, pues ambas son bienes intrínsecos. Ibíd., pp. 53-54. Por su parte, LISI (2004b: 117) denomina a la eudaimonía primaria "felicidad contemplativa" y a la secundaria, "felicidad política" y asegura que ambas formas no son contradictorias para el hombre, pues "en tanto ser humano y que habita con otros también debe escoger llevar a cabo acciones relacionadas con la virtud humana $\mathrm{y}$, por ende, necesitará también de todos aquellos bienes externos y corporales que son necesarios para su actividad humana" Ibíd., p. 118. A la luz de ello, Lisi reconoce que la felicidad filosófica solo puede obtenerse en la pólis y, en este sentido, se trata de una felicidad política, "porque solo puede darse en la comunidad organizada de una determinada manera y entre ciudadanos, i.e. es solo posible en un sistema que garantice la igualdad de los miembros que activamente participan de la comunidad." El autor adopta una interpretación dominante de la eudaimonía, por ende, considera a la felicidad política una forma derivada, ya que estrictamente solo es feliz el sabio. A su juicio, la felicidad contemplativa presupone la felicidad política como condición necesaria en el contexto del régimen político ideal, lo cual plantea el problema de si es posible alcanzar la felicidad contemplativa fuera de ese régimen.

${ }^{6} \mathrm{El}$ texto que tradicionalmente se considera más relevante para reconstruir la posición aristotélica con respecto a la relación de los géneros de vida es el del final de la $E N$, en donde — según 
práctica que allí establece como la mejor (áristos bíos ho praktikós, Pol. 1325b16). ${ }^{7}$ Ya sea que se postule una contradicción entre ambas obras respecto de la forma de vida a la que apunta en cada una (BERTELLI 2004: 188; GASTALDI 2004:178) ${ }^{8}$ o bien se afirme una perfecta conformidad (LISI 2004: 120) ${ }^{9}$ o incluso se reconozca la correspondencia entre la jerarquía de la felicidad de EN X 78 y la de la práxis en Pol. VII 3 (SUÑol 2013: 41), en cualquier caso es preciso esclarecer, en la medida de lo posible, cuál es y en qué consiste de manera concreta la vida más elegible en el régimen político ideal que bosqueja en los dos últimos libros de la Pol. y, en particular, si se admite que tiene un carácter estrictamente filosófico, cómo el Estagirita lo concilia con las responsabilidades cívicas que todo ciudadano debe desempeñar en dicho régimen. Con vistas a ello, en la primera parte, analizo de manera detallada la argumentación del pasaje de Pol. VII 3. En la segunda, examino los principios teóricos sobre los que se sustenta la construcción del régimen y que Aristóteles presenta en Pol.

GASTALDI (2004:167) — hay una reivindicación absoluta de la superioridad de la vida filosófica. Sin embargo, como advierte la autora, son los capítulos iniciales de Pol. VII en donde se encuentra la discusión más amplia sobre esta cuestión y es posible reconstruir la compleja articulación del debate que sobre la relación entre la vida filosófica y la política se desarrolló desde los últimos años de la Guerra del Peloponeso y que refleja la "crisis de la política". Ibíd., pp. 169, 175. Más allá del carácter ontológica y epistemológicamente incondicionado que Aristóteles le reconoce a la actividad teorética en $E N$ X 7-8, entiendo que como forma de vida está sujeta a las limitaciones y restricciones de la existencia humana, lo cual el propio Estagirita reconoce $\mathrm{y}$, en tal sentido, considero inadecuado hablar - tal como hace GASTALDI - de una superioridad absoluta de esta forma de vida.

${ }^{7}$ Muchos traductores e intérpretes prefieren traducir este empleo de praktikós en el sentido de "activo". En principio, parecería que esta traducción permitiría eludir la dificultad que supone la subsunción de lo teórico en la esfera de lo práctico como su forma más alta y la aporía que plantea hablar de una práxis teórica. Sin embargo, el problema conceptual persiste aunque se lo intente evitar terminológicamente. El propio Aristóteles es quien reconoce la ambigüedad de su postura al afirmar que los defensores de ambos bíoi dicen correctamente unas cosas, pero no otras (Pol. 1325a23-24). Por esta razón, me inclino por la traducción que más claramente refleja esta tensión irresuelta. Cfr. SANTA CRUZ y CRESPO (2005); KRAUT (1997: 74).

${ }^{8}$ Sobre la interpretación de ambos, véase, n. 11 .

${ }^{9}$ A la luz de la tesis discontinuista originalmente sostenida por Rowe, Lisi (2004b) hace un detallado análisis de los argumentos expuestos en EE, EN y Pol., y concluye que: "la concepción aristotélica de la felicidad tiene una unidad sustancial en todos los tratados que se han conservado" Ibíd., p. 120. En respuesta a las críticas de Lisi y a raíz de su trabajo con BROADIE, Rowe (2004: 123-124) rechaza el discontinuismo que previamente defendió y reconoce que la división de la eudaimonía en dos formas ideales es una bifurcación en la vida que se caracteriza por una actividad excelente. En el caso de la vida contemplativa incluye también una actividad práctica excelente y en el de la vida política no necesariamente involucra una carrera política, sino la del buen ciudadano. En este sentido, Rowe reconoce un cierto quietismo en la comprensión aristotélica de la vida política y llega incluso a identificar la participación política moderada del ciudadano con el ocio. Ibíd., pp. 132-133. Los trabajos de LISI y de RowE muestran que aun cuando se acuerde en la continuidad de la comprensión aristotélica de la eudaimonía en la $E N$ y en sus distintas obras ético-políticas, la oposición entre la tesis dominante y la inclusiva parece insuperable. 
VII 13-15, los cuales resultan relevantes para esclarecer la cuestión de los bioi. Por último, me ocupo de las referencias que hace a los filósofos en Pol. VIII, las que a pesar de no haber despertado interés en la exégesis, permiten determinar la función que estos desempeñan en la aríste politeía.

\section{El bíos praktikós como bíos hairetótatos en Pol. VII 3}

El capítulo más relevante para elucidar estas preguntas es Pol. VII 3 no solo porque a través del debate dialéctico que establece entre los defensores de ambos bíoi expone su propia comprensión política del ideal de vida, ${ }^{10}$ sino fundamentalmente porque de manera expresa asegura que la vida mejor es la práctica, tanto para la ciudad en común como para cada uno (Pol. VII 3 1325b15-16). A primera vista, parecería que esta afirmación contradice el ideal contemplativo tal como aparece ejemplarmente expuesto en el final de la $E N,{ }^{11}$ sin embargo es importan-

${ }^{10}$ Las razones que esgrime a favor y en contra de los defensores de ambos bioi permiten esclarecer la forma de vida que el propio Aristóteles defiende, a la vez, que ponen de manifiesto su naturaleza intrínsecamente política. En efecto, en estos capítulos deja en claro que la elección de la forma de vida es inseparable del modo de dominación. Independientemente de la interpretación que se adopte con respecto a cuál es para el Estagirita la vida más elegible, es indudable que ella presupone un régimen de dominación entre iguales, esto es, de carácter político. La superioridad moral de la vida del hombre libre sobre la del amo (Pol. 1325a24-25), el rechazo a la confusión de la dominación política con la despótica (1325a27-28), el repudio al imperialismo (1324b23-36) y al ejercicio de la violencia (1325b1-3), el reconocimiento de la legitimidad de la dominación política (1325a7-10; 1325a28-30), la alternancia en el ejercicio del poder entre iguales (1325b7-8), el carácter práctico de la felicidad mediante la identificación de eudaimonía y eupragía (1325a22-23, 31-34), la preferencia de la virtud y la conjunción de esta con la capacidad de actuar (1325b12-13) son algunos de los aspectos de la posición aristotélica y revelan que esta conjuga elementos de ambas opiniones o, más precisamente, de la reconstrucción que hace de cada una de ellas.

${ }^{11}$ Como se anticipó, tal es la postura que adoptan Lucio Bertelli y Silvia Gastaldi. El primero se refiere a la sensación de incomodidad a la que da lugar la "clara contradicción" ("palese contraddizione") entre la preferencia - sin término medio - de la vida teorética en EN X 7 y la elección de la vida práctica en $P o l$. VII 3, a la cual se le atribuía un nivel secundario en EN X 8. Bertelli (2004: 188) sostiene que el juicio de contrariedad solo se justifica a partir de la pretensión de coherencia del sistema aristotélico, conforme a la cual la única versión auténtica y definitiva de eudaimonía es la de $E N$. Según el autor, dicha pretensión ha llevado a desvalorizar las restantes definiciones atestiguadas en Protr., en EE y, en particular, a desconocer la especificidad política de su tratamiento en Pol. VII. En definitiva, el autor critica a quienes hablan de contradicción entre EN X y Pol. VII, al tiempo que reconoce su existencia, si bien no intenta salvarla. Personalmente, acuerdo con BERTELLI sobre la importancia de recuperar la significación política del proemio ético de Pol. VII, pero entiendo que reconocer una posible tensión entre ambas obras no presupone una demanda de sistematicidad. Por el contrario, las consideraciones que el propio Aristóteles hace sobre la falta de autonomía del hombre para el ejercicio de la actividad contemplativa en EN X 7-9 y la redefinición de práxis en Pol. VII 3 prueban que no existe una verdadera contradicción entre el ideal de vida que el Estagirita defiende en ambas obras. Para una argumentación más detallada sobre esta cuestión, cfr. 
te advertir que la misma se desprende de la identificación de la eudaimonía con la eupragía (Pol. 1325b14-16) y, en tal sentido, lo que Aristóteles parece querer resaltar a través de ella es el hecho de que la eudaimonía como fin último del hombre $\mathrm{y}$, por ende, de la comunidad es una cierta clase de actividad (he gàr eupraxía télos, hóste kai prâxís tis, 1325b21). De hecho, mediante la re-definición de lo práctico que de manera inmediata propone (Pol. 1325b16-23), reconoce que la práxis no necesariamente se limita a la que es de tipo instrumental y establece como su forma superior los pensamientos y contemplaciones que tienen su fin y su causa en sí mismos. ${ }^{12}$ De este modo, afirma el carácter práctico de la actividad que no es más que para sí misma y su preeminencia respecto de

SuÑOL (2013: 17-41). Por su parte, GASTALDI (2003: 17) habla del carácter aporético que este tema tiene en el pensamiento de Aristóteles, pues asegura que "ogni tentativo di costruire un disegno teorico coerente tradisce la problematicita dell'approccio aristotélico al tema dei generi di vita, in cui l'atopia del filosofo continua a rappresentare l'elemento saliente, il segno di un'aporia irrisolta $[\mathrm{sic}]$ '. Si bien la autora reconoce que la superioridad de la vida filosófica es un motivo común en los textos aristotélicos dedicados a la cuestión de los géneros de vida, admite que la separación entre el filósofo y el ciudadano nunca es resuelta de manera definitiva. De hecho, en su trabajo de 2004 afirma que el privilegio de la theoría basado en un criterio puramente axiológico en EN X no se corresponde con su ausencia del mejor régimen de Pol. VII-VIII, en donde el ideal del bíos hairetótatos como vida de la virtud ética responde al intento de conciliación e integración en el marco del debate dialéctico allí planteado. Ibíd., p.178.

${ }^{12}$ A mi entender, esta jerarquía de la práxis es uno de los indicios más importantes que abona una comprensión estrictamente filosófica del ideal aristotélico de vida; si bien es cierto que el carácter epexegético del pasaje revela que no es este el sentido que usualmente el filósofo le otorgaba a lo práctico. Los intérpretes suelen remitir a otros pasajes del corpus en los que se evidencian empleos más o menos afines a esta ampliación semántica del concepto. Así por ejemplo, en EN V $11129 \mathrm{~b} 31 \mathrm{ss}$. —en el contexto de la consideración sobre la justiciaAristóteles apela a la contraposición pròs héteron-kath' hautón, pero la valoración que hace aquí es diametralmente opuesta, ya que el carácter distintivo de la justicia y lo que determina su perfección es el hecho de ser respecto de otro. Por el contrario, en EN X 7 1177a27ss., el Estagirita habla de la autarquía del sabio comparándola con la heteronomía del justo (ho mèn dikaois deitai pròs hoùs dikaiopragései kaì meth hônn, b30-31) y afirma que el primero aun en soledad (kath'hautòn) es capaz de contemplar y cuanto más sabio sea, más (1177a34). Aunque Aristóteles emplea la palabra enérgeia $(1177 \mathrm{a} 20$; b19) para referir a la actividad contemplativa y práxis (1177b6-7; 16), para las actividades políticas y guerreras, lo que conceptualmente allí afirma respecto de la mayor autonomía de la primera no contradice lo dicho en el pasaje de Pol. VII 3, sino que está en conformidad con él. También se aduce que en EN VII $141154 \mathrm{~b} 24$ emplea práxis en un sentido más amplio que el usual, que abarcaría incluso al pensamiento puro: "Si la naturaleza de alguno fuera simple, la acción más placentera sería siempre la misma (he autè prâxis)". A juicio de NEWMAN (1902: 337 ad 16), la expresión he autè prâxis debe referir ("must refer") a la actividad contemplativa. A pesar de que Aristóteles en ningún momento alude a ella, la analogía con la divinidad, en particular, con la actividad de la inmovilidad (enérgeia allà kaì akinesías, EN 1154b27), justifica esta interpretación. Asimismo, entre los pasajes que se consignan está De Anima 407a23-24, donde afirma que todas las intelecciones prácticas (e incluso las teóricas) son con vistas a algo distinto de sí, excluyendo así la posibilidad - admitida en Pol. VII 3- de que existan pensamientos e intelecciones prácticos que no son más que para sí mismos, es decir, de carácter no instrumental. Aun cuando en ambos pasajes difiere lo que cae bajo la esfera de lo práctico, es claro el contraste que existe entre ellos. La consideración de estos diversos pasajes pone de manifiesto la singularidad de la rede- 
la práxis instrumental. Por medio de la alusión a los pensamientos y contemplaciones (theorías kaì dianoéseis, Pol.1325b20-21) ${ }^{13}$ introduce una dimensión cognitiva que hasta ese momento estaba ausente de la discusión política. ${ }^{14}$ Asimismo, el énfasis en el carácter práctico de la actividad intelectual se vincula al contexto dialéctico, específicamente, a la defensa de la inacción (tò aprakteîn) que postulan quienes proponen el alejamiento de la política (Pol. 1325a31-32). ${ }^{15}$ Más allá de las determinaciones contextuales, esta jerarquía de

finición de práxis propuesta en Pol. VII 3, pues más allá de lo que tácitamente pueda inferirse de ellos, en ningún otro Aristóteles subsume a lo teorético como forma suprema de lo práctico. ${ }^{13}$ Distinto es el caso de la referencia a tês politikếs dianoías kai theorías en Pol. VII 2 1324b19-20. Dicha alusión forma parte de un interludio programático en el que Aristóteles asegura que la indagación del mejor régimen es la tarea propia (érgon) del pensamiento y la especulación políticas, pero no lo es investigar lo preferible para cada uno, que es una tarea secundaria (párergon). El desarrollo posterior de la argumentación revela que es de esta cuestión de la que efectivamente se ocupa en el resto del capítulo. Como señala BerTELLi (2004: 185-186), el fílósofo se inclina por el párergon. A diferencia del énfasis que BERTELLI pone en la separación entre ética y política en el pensamiento aristotélico, entiendo que perteneciendo ambas cuestiones a la ciencia política, las dos son, en sentido estricto, asunto (érgon) de dicha ciencia. El carácter secundario (parérgon) de la indagación sobre lo preferible para cada uno simplemente remite al método de investigación, pues como advierte DEPEW (2009: 399-400): la ética aristotélica no está subordinada ni es superior a la política, simplemente es una ciencia política. No obstante, esta identidad de fondo no impide establecer una articulación interna entre los ámbitos que cubren ambas disciplinas y en virtud de la cual, la ciencia política se desdobla — como asegura GuARIGLIA (1979: 18-19)— en dos grandes capítulos: el de la ética y el de la política.

${ }^{14}$ Como advierte BerTelli (2004: 194), hasta aquí la dimensión cognitiva no era puesta en consideración ni en relación con los defensores de la vida filosófica ni con los de la vida política, sino que la postura de ambos era valorada o criticada por su relación con el poder político. Según el autor, este "extraño" vuelco hacia la dimensión teórica está determinado por el contexto dialéctico. Véase, n. 15.

${ }^{15}$ Tanto Gastaldi como BerTelli explican esta ampliación semántica de práxis a partir del contexto dialéctico en el que se plantea la cuestión de los bioi en Pol. VII 2-3. Sin embargo, ambos la interpretan de manera distinta. Según GASTALDI (2003: 62-63; 2004: 178), a través del "sorprendente" curso que de manera inmediata adquiere la argumentación, la noción de práxis es sometida a un singular proceso de ampliación, por el cual se convierte en un vasto denominador en el que confluyen ambos bioi. El debate dialéctico puesto en escena en el capítulo dos permite comprender el sentido de esta argumentación, que — según la autora — apunta a conciliar e integrar las posiciones antagónicas al constituir un sentido amplio y global de práxis, que está ausente de EN X. A su entender, mediante la referencia a su función arquitectónica Aristóteles indica que a la theoría le compete la tarea de elaborar las normas. De hecho, GASTALDI (2003: 64) identifica en este pasaje tres planos del pratteîn, a saber: la práxis que lleva a la realización del comportamiento virtuoso, la actividad teórica en sentido estricto y la actividad directiva que - originándose en esta forma superior de saber - tiene por objetivo la reglamentación de la actividad política. Véase n. 27. Por su parte, BERTELLI (2004:194) sostiene que esta "extraña" reorientación del bios praktikós hacia la dimensión teórica responde a la misma exigencia dialéctica que, sin discutir la opción especulativa del bios theoretikós, subrayaba el defecto de la elección del aprakteîn, irreconciliable con el axioma de la identidad de eudaimonía con eupraxía, y que ahora lo lleva a destacar que el bios praktikós no lo es solamente a nivel de acción heterónoma, sino que contempla un nivel de elaboración teórica y directiva superior a aquel. Respecto del carácter directivo que GASTALDI le atribuye a la práxis 
la práxis es congruente con la perspectiva intelectualista general de Aristóteles y no parece posible concebirla como una distinción interna a la actividad práctica (pace BERTELli 2004), ${ }^{16}$ en la medida en que él mismo reconoce que se consideran supremas las acciones de quienes dirigen con su pensamiento incluso las acciones externas (Pol. 1325b21-23), lo cual pone de manifiesto que alude no solo a estas últimas, sino principalmente a los pensamientos y contemplaciones que tienen su propio fin y su causa (tàs autoteleîs kaì tàs hautôn henéken theorías kaì dianoéseis, b20).

En concordancia con la mirada, a la vez, individual y comunitaria que adopta desde el comienzo del libro (Pol. VII 1 1323a19-21), Aristóteles aplica el argumento sobre la jerarquía de la práxis a la organización política, equiparando la forma suprema de acción con aquellas ciudades que se han establecido conforme a sí mismas y que han elegido vivir de ese modo (Pol. VII 3 1325b2427) y advierte que estas no son inactivas, pues la acción se ejerce sobre las partes que las componen, es decir, sus distintas comunidades (koinoníai). Al respecto, cabe recordar que en Pol. VII 2 1324b41-a5 plantea como hipótesis la existencia de una única ciudad feliz establecida conforme a sí misma, que carece de enemigos, cuyo fin no es la guerra ni la dominación, sino la felicidad del régimen, la cual le permite al Estagirita ilustrar el ideal de una ciudad pacífica. Aun cuando no propone el aislamiento del mejor régimen, las ciudades a las que alude en el pasaje final de Pol. VII 3 son semejantes a aquella del capítulo dos, pues al estar focalizadas en su organización interna escapan del modelo imperialista imperante, al cual Aristóteles critica de manera reiterada (Pol. VII 2 1324b5-41; VII 3 1325a35-b10). En efecto, como revela el diseño mismo de la pólis ideal, se trata de un régimen pacífico en el que las actividades bélicas tienen un valor meramente instrumental y en el que la acción se focaliza en la organización interior, especialmente, en la educación.

Finalmente, Aristóteles concluye el argumento trazando un paralelismo entre las ciudades y los individuos (Pol. VII 3 1325b25-28). ${ }^{17} \mathrm{Al}$ igual que $\mathrm{Pol}$.

teórica, BERTELLI (2004: 195 n.6) asegura que: "Tutto questo si podrà dedurre dal termine architekton, ma non è positivamente indicato nel testo".

${ }^{16}$ Bertelli (2004: 194 n.1) asegura que lo que hay en juego aquí es una jerarquía que solo atañe a la actividad práctica y que, por lo tanto, no implica una defensa de la vida filosófica. Sin embargo, el vocabulario que Aristóteles emplea en el pasaje: el comparativo polù mâllon, los superlativos málista, kuríos y el participio toùs architéktonas dan cuenta de la superioridad absoluta de una forma de práxis que no puede limitarse a la actividad práctica, especialmente, a la luz de la expresa referencia a los pensamientos y contemplaciones. GASTALDI (2003: 139 n. 4) reconoce aquí una gradación: "una sorta di climax ascendente [sic]".

${ }^{17}$ KRAUT (1997:75 ad b27-28) sostiene que el Estagirita no alude aquí a la actividad de las partes que componen al individuo, sino al hecho de que los seres humanos pueden ser activos incluso cuando viven para sí mismos. 
VII 1 (1323b23-26), en donde apela a la divinidad para explicar la naturaleza de la eudaimonía en los hombres, Aristóteles recurre aquí a la comparación con la divinidad y el orden cósmico como paradigmas de este tipo de acción, ${ }^{18}$ para quienes no existe ningún tipo de práxis externa (1325b28-30). ${ }^{19}$ Aunque se ha intentado atribuir un significado político a esta comparación, no parece posible argüir que hay aquí una tácita defensa de la monarquía macedónica, la cual se sustentaría en una propuesta de distanciamiento de la participación política (pace KELSEN 1977). ${ }^{20}$ Por el contrario, el filósofo de manera reiterada plantea la alternancia entre todos los ciudadanos del régimen (Pol. 1325b7-8; 1332a 34$35 ; 1332$ b 24-26). De hecho, no solo no promueve el alejamiento de la vida cívica, sino que - como deja en claro en este proemio - la vida más elegible y, por ende, la felicidad únicamente pueden alcanzarse en el contexto de un régimen pacífico en el que la dominación es de carácter político. ${ }^{21}$ Más allá de su posible interpretación política, lo cierto es que la correspondencia entre la acción humana no instrumental - tanto la de carácter individual como la cívica- con la actividad divina abona una comprensión fuerte de la forma de vida

${ }^{18}$ GASTALDI (2003:65) asegura que Aristóteles apela a la comparación con la divinidad con el propósito de ofrecer una prueba irrefutable a su argumento sobre la ampliación semántica de práxis: "L'identificazione della theoria con la forma più elevata e pregnante di azione constituisce, ed Aristotele ne è ben consapevole, una sfida potente alla concezione corrente di praxis, e pertanto questa ricodificazione debe essere sostenuta da autorevoli mezzi di prova [el destacado es mío]." KELSEN adopta una postura semejante, si bien le atribuye una connotación política. Véase n. 20.

${ }^{19}$ KRAUT (1997: 75-76) encuentra en esta comparación un indicio importante para establecer la datación de las obras éticas, pues sostiene que la "reticencia" de Aristóteles a remitir al argumento semejante de $E N$ X 8 (1178b8-32) -como luego sí lo hace con formulaciones de la $E E-$ revela que aún no había escrito esa obra. Aunque admite que es poco probable que en algún momento el Estagirita haya tenido dudas sobre la superioridad de la vida filosófica, el autor observa una progresión natural en el tratamiento de la cuestión en sus obras éticas, la cual -a su entender- refleja una necesidad creciente de escribir acerca de la rivalidad entre filósofos y políticos: "[...] the Eudemian Ethics does not explicitly compare the two lives, the Politics does so but not decisively come to a conclusion, and the Nicomachean Ethics fully explore the issue and champions the philosophical life". Para BERTELLi (2004: 195) esta hipótesis es admisible. Por el contrario, me parece cuestionable realizar este tipo de inferencias basadas en la presencia o ausencia de referencias a otras obras de Aristóteles, en particular, en estos dos últimos libros de la Pol. que presentan grandes dificultades textuales y, más aún, teniendo en cuenta los problemas de redacción que específicamente se evidencian en el proemio.

${ }^{20}$ Según Kelsen (1977: 185-186), es en este punto de la Pol. en donde la ética y la metafísica confluyen y revelan su verdadera significación política, por cuanto Aristóteles procura ofrecer una justificación incuestionable de la vida contemplativa, la cual es ajena a toda participación política y completamente opuesta al ideal democrático ateniense: "God himself justifies the ideal of a non-political life". El hecho de que este ideal sea -según el autor- remoto a la participación política, conlleva una tácita defensa de la monarquía hereditaria, muy probablemente macedónica, aunque como el propio KELSEN reconoce: Aristóteles nunca dice expresamente ni siquiera sugiere que ella sea la mejor forma de gobierno. Ibíd., p. 171.

${ }^{21}$ Sobre la importancia del contexto político, véase n. 56. 
que Aristóteles defiende aquí, frente a quienes — como veremos - aseguran que no se trata de un ideal filosófico, sino simplemente cultural.

Aristóteles no aclara en el pasaje de Pol. VII 3 qué actividades comprende el bios praktikós, si remite de manera exclusiva a la filosofía como modelo de actividad que no apunta más que a sí misma o si, de manera más general, refiere a otras actividades de esta naturaleza; tampoco explica cómo se vincula esta forma de vida que se sustenta en un tipo de práxis a la que podríamos denominar "interna" con otras formas de vida, especialmente, la política, cuyas acciones son meramente instrumentales. Esta indefinición por parte del Estagirita ha dado lugar a las más diversas interpretaciones. De hecho, en la literatura actual no hay acuerdo no solo con respecto a cómo se relacionan los dos géneros de vida, ni siquiera a cuál de ellos Aristóteles defiende aquí. Hay autores que entienden que se inclina por el ideal contemplativo sin rechazar plenamente la vida política (JAEGER 2011; KELSEN 1977)22; otros sostienen que no propone un único ideal, sino que de sus consideraciones se desprenden dos (DEPEW 199123; DEMONT $1990^{24}$ ) o tres (COOPER 2010; 2012) ${ }^{25}$ modos de vida posibles; también hay quie-

\footnotetext{
${ }^{22}$ Tal es, por ejemplo, la interpretación de JAEGER (2011: 323-324), para quien el ideal aristotélico es un medio entre dos extremos radicales, ya que combina la vida ideal filosófica con una concepción activa del Estado, en la que la contemplación filosófica es presentada como una "especie de 'acción creadora'". Según KeLSEN (1977:184), Aristóteles defiende el ideal contemplativo sin rechazar plenamente la actividad política.

${ }^{23}$ DePEw (1991: 352) asegura que en Pol. VII 1-3 Aristóteles no pretende privilegiar ni politizar la vida contemplativa, o redefinirla de manera arbitraria como una vida activa. Antes bien, rechaza ambas formas de vida, esto es: la de los intelectuales apolíticos y los políticos convencionales, como modelos para la vida feliz del individuo y del Estado. Afirmar que la contemplación es una actividad le sirve al Estagirita para cancelar ambos extremos y construir un espacio en el que los compromisos politicos y contemplativos pueden fundirse en una forma de vida sui generis - a la que el autor admite que se la llame 'filosófica'-dedicada a todas las actividades intrínsecamente valiosas. Más precisamente, DEPEW (1991: 358-359) sostiene que son dos las vidas posibles, la del intelectual políticamente abierto y la del que es genuinamente político, las cuales divergen solo como una función de cada ciudadano tratando de realizar sus propias capacidades más altas (Pol. VII 14 1333a29-30).

${ }^{24}$ DEMONT (1990: 349) sostiene que la vida filosófica es tan fundamental y esencial como la vida política. La única forma de dar cuenta de la simultaneidad de estas dos actividades supremas del hombre es analizar la teoría aristotélica de la acción y del alma, y observar "un scission a l'interieur de la raison' qui dégage la possibilité de deux vies rationnelles (et donc bonnes), mais distinctes". A su juicio, el fundamento de la coexistencia de la vida política y la filosófica está en EN VI 2 1139a 6-8, donde Aristóteles distingue las dos partes del alma racional. Véase n. 30.

${ }^{25}$ En su libro recientemente publicado, COOPER (2012: 137-139) asegura que para Aristóteles la vida absolutamente más feliz es la contemplativa. No obstante, reconoce que la filosofía como forma de vida es doble, ya que comprende, primariamente, la teorética y, de manera secundaria, la filosofía de las cosas humanas. Además de los contemplativos, CoOPER sostiene que hay otros dos tipos de agentes virtuosos: los líderes políticos y los ciudadanos dedicados a su vida privada. Todos ellos e incluso la gente meramente decente, educada en un régimen como el descripto en los dos últimos libros de la Política reconocen que la vida más elegible es
} 
nes aseguran que el pasaje no deja para nada en claro cuál de los dos bíoi es superior (BROWN 2011). ${ }^{26}$ Algunos niegan la existencia de una oposición sustancial y le otorgan una función directiva a la práxis teórica (GASTALDI 2003). ${ }^{27}$ Otros postulan una vida en la que se conjugan la virtud moral o política con una virtud especulativa de cierta clase y apelan a diversas estrategias interpretativas, sea al reconocimiento del contexto político de la investigación (LORD 1978) ${ }^{28}$, sea a una interpretación comprensiva de la felicidad (IRWIN 1990) ${ }^{29}$, sea a criterios psicológicos y aun ontológicos sobre su primacía respectiva (DEMONT 1990). ${ }^{30}$ Incluso hay quienes afirman —en conformidad con la $E N$ - que la feli-

la contemplativa y aunque no la persiguen como fin último de sus vidas privadas organizan la vida política común de forma tal que hacen posible esa clase de vida.

${ }^{26}$ Aunque Brown (2011: 4 n. 12) no se ocupa específicamente de estos pasajes, asegura: “At Politics VII 2-3 Aristotle leaves entirely unclear whether the political or philosophical life is superior."

${ }^{27}$ A juicio de Gastaldi (2003: 64), Aristóteles le confiere aquí una función directiva a la indagación teórica, a la cual le corresponde la tarea de elaborar las normas "i princìpi generali cui le azioni- e pertanto la prassi questa volta intesa in senso stretto- devono adeguarsi". Según la autora, se trata de una forma de práxis que aunque se ejerce con la facultad intelectual no se ejercita con vistas al puro conocer, sino que asume una función directiva, que es parangonada con la figura del constructor en Pol. 1325b23: toùs taîs dianoíais architéktonas. Ibíd., p. 139. Al ampliar la noción de práxis, Aristóteles logra dar una respuesta satisfactoria a los oponentes del debate dialéctico por entonces vigente sobre las formas de vida: "mostrando che non existe una sostanziale opposizione tra la vita pratico-politica e la vita dedita all'esercizio della theoria e della dianoia [el destacado es mío]." Ibíd., p. 141. De este modo, convergen el hacer práctico propiamente dicho y la actividad intelectual, ya sea por sí misma o con vistas a la gestión ético-política de la ciudad. Sobre los tres sentidos de práxis que GASTALDI identifica, véase, supra, n. 15.

${ }^{28}$ LORD (1978: 346) destaca que este argumento se inserta en un contexto político de investigación. De ahí que aunque para Aristóteles la vida más feliz sea la filosófica, en el mejor régimen lo es una aproximación a la vida especulativa posible en el nivel de la política, la cual requiere "a judicious admixture of practical, political or moral virtue with 'speculative' virtue of a certain kind." Ibíd., p.354. En definitiva, se trata de una forma de vida que combina la especulación filosófica con la acción política.

${ }^{29}$ IRWIN (1990: 81), quien asume una interpretación comprensiva de la felicidad, sostiene que la vida completa incluye la actividad política y la filosófica, pues ambas son bienes intrínsecos de la eudaimonía. Ante la objeción que el propio Aristóteles plantea en EN X 7 de que las actividades externas constituyen obstáculos para la vida primariamente feliz de la contemplación, el autor reconoce en la Pol. dos posibles respuestas implícitas. En primer lugar, asegura que en la ciudad ideal la actividad política no es tan pesada para el hombre justo como lo es en los regímenes no ideales. Además, el desarrollo de ambos tipos de vida no es simultáneo, sino sucesivo y en la vejez, libre de las cargas políticas (Pol VII 9), los hombres pueden dedicarse a la vida contemplativa. IRWIN reconoce que el Estagirita no ofrece esta división temporal como una solución a la dificultad de los componentes teóricos y prácticos de la felicidad, pero sugiere una solución posible.

${ }^{30}$ Demont (1990: 352) admite que en la Pol., la prudencia (que puede tener su fin en sí misma) y la sabiduría son puestas en un mismo rango, pero el criterio definitivo que determina la superioridad de la sabiduría está dado por la jerarquía ontológica, según la cual el hombre no es lo mejor que hay en el mundo. Asimismo, asegura que el modelo del pensamiento puro, como pensar del pensar encuentra su fundamento en la Metafísica en el ocio divino, que es la mani- 
cidad consiste en una vida estrictamente filosófica ${ }^{31}$ en el seno de la pólis ideal (LISI 2004)..$^{32}$ Asimismo, puede argüirse que la indefinición del pasaje refleja la ambigüedad característica de los pensadores del siglo IV a. C., quienes habrían intentado conciliar el ideal filosófico del ocio (scholé) - heredero de la tranquilidad (hesuchía) arcaica y del rechazo a la intrigas (apragmosúne ) de la literatura democrática - con la ideología dominante de la acción. ${ }^{33}$ En términos generales, la mayoría de los autores interpreta el pasaje como un intento de conciliación entre ambas formas de vida. Frente al predominio de este tipo de lecturas conciliatorias, BERTELLI (2004: 195) sostiene que Aristóteles no tiene intención alguna de transformar el bíos praktikós en una especie de bios theoretikós ni pretende lograr un compromiso entre ambos y postula la existencia de una clara contradicción entre la defensa del ideal contemplativo del final de la $E N$ y la afirmación del bíos praktikós en Pol. VII 3. ${ }^{34}$ A su juicio, el ideal de vida al que el

festación de la superioridad del ocio teorético. Ibíd., pp. 354-355.Véase, supra, n. 24.

${ }^{31}$ KrAut (1997:73) asegura que Aristóteles defiende aquí la vida filosófica frente a la acusación de inactividad, pero reconoce que los argumentos del filósofo se ven afectados por el hecho de que no explica de manera precisa en qué consiste ser activo.

${ }^{32}$ Puesto que Lisi (2004b: 112) suscribe a una comprensión dominante de la eudaimonía, no propone una perspectiva conciliatoria de ambos bioi. No obstante, su reconocimiento de que la felicidad solo puede darse en el contexto de la pólis, le permite afirmar que: "El fin del hombre es llegar a ser un ciudadano de una polis y dentro de ésta, el fin supremo es el de llegar a convertirse en un sabio, un filósofo que actualiza lo divino presente en el ser humano [el destacado es mío]." Ibíd., 119. La ampliación de práxis le sirve "para reformular una idea de la vida teórica fundada en la práctica política". Véase n. 48.

${ }^{33}$ Demont (1990) no solo muestra la génesis y el desarrollo del ideal de la tranquilidad en las ciudades griegas de los siglos VII al IV a. C., sino que fundamentalmente destaca su carácter cívico. La prolongación del ideal arcaico de la hesuchía y de los debates atenienses sobre el rechazo a las intrigas (apragmosúne) llevó a los pensadores del siglo IV a.C., Jénofanes, Platón, Isócrates y Aristóteles, a conciliar las necesidades de la acción política con la tranquilidad y a elaborar una teoría del ocio (scholé) como fin de la vida humana y condición de la felicidad. Aunque el vulgo podría considerar al ocio como inacción, en realidad, viene a designar, la actividad más noble. La evolución semántica de los términos que designan la tranquilidad revela -según DEMONT (1990: 12-17; 428)- que estos son principalmente conceptos cívicos, que no implican una completa eliminación de la acción - especialmente política-, antes bien, la suponen. La vida del retiro del mundo cívico y humano es ajena al pensamiento griego arcaico y clásico, y habrá que esperar hasta los primeros siglos de la era cristiana para que se desarrolle como ideal de vida, gracias a la confluencia de diversas tradiciones como el judaísmo alejandrino, el neopitagorismo, la gnosis y el cristianismo. Ibíd., p. 402-403. CARTER (1986:173) también reconoce el carácter social de la vida contemplativa: "Ultimately, there is no life outside the city; even fourth-century theorists, while setting the Contemplative Life above all others, still conceived it as something taking place within the context of city life. It is a social existence [el destacado es mío]." De manera más reciente, Brown (2009: 489-492) señala que Platón y Aristóteles elaboran una defensa filosófica del retiro de la vida política con vistas a la contemplación, pero ambos aceptan los supuestos implícitos de la ideología dominante. Sobre la interpretación de BROwN, véase n. 58.

${ }^{34}$ Bertelli (2004:195) rechaza este tipo de lecturas, las cuales - a pesar de sus divergenciasintentan conciliar ambos bioi y sostiene que: “ [...] probabilmente l' alternativa vita 
Estagirita apunta en la Pol. no es en modo alguno el de la filosofía, sino antes bien el de la cultura y, en virtud de ello, habla de una "ciudad 'filosófica' sin filosofía" ${ }^{35}$ Precisamente, respecto de esta cuestión se plantea uno de los principales puntos de desacuerdo en la discusión académica, ya que buena parte de los intérpretes niega que la contemplación sea el fin último o exclusivo del mejor régimen, por ejemplo: SOLMSEN (1964) ${ }^{36}$, LORD (1978) $)^{37}$, DEPEW (1991) ${ }^{38}$;

teorética/vita pratica di $E N \mathrm{X}$ o non existe ancora o non è ritenuta pertinente ad una methodos sulla 'vita preferibile' nella 'città secondo i voti'". Por el contrario, puede argüírsele que, en realidad, la dicotomía tradicional entre la vida política y la vida filosófica no aparece como tal en EN X 7-8, sino en los capítulos iniciales de Pol. VII y es el propio Aristóteles, quien la establece como condición metodológica para investigar el mejor régimen. Además, parece riesgoso apoyarse - como lo hace BERTELLI - en la hipótesis de KRAUT (1997) sobre la "evolución" de este problema en el pensamiento aristotélico, pues no hay dudas de que el debate sobre los bíoi está presente en toda su obra ética. Véase, supra, n. 19.

${ }^{35}$ Apoyándose en Pol. VII 13-15, BerTelLi (2004:198) concluye que no es lícito atribuir a Aristóteles la intención de proponer el bios theorétikós como el fín de la ciudad ideal, a la cual caracteriza como una "una città 'filosofica' senza filosofia". De este modo, despoja al bíos praktikós de Pol. VII 3 de todo contenido teorético, interpretándolo próximo al ideal cultural ateniense. Véase n. 47.

${ }^{36}$ Solmsen (1964: 216-219) asegura que el fin de la vida de los ciudadanos del mejor régimen es el ocio (scholé). A su juicio, esta es la gran innovación de Aristóteles respecto de su maestro (Ibíd., p. 207), pero advierte que no se trata de una variedad intelectual o filosófica, sino moral: "Aristotle clearly makes allowance for the fact that the majority of citizens, even by his rather selective definition of citizen status, are not philosophers and would not find their happiness in theoretical pursuits". Ibíd., p. 218. En efecto, la música (en su forma más elevada) como eje de la educación no tiene un interés cultural, antes bien apunta a la formación del carácter. No obstante, aunque ello pueda muy probablemente redundar en mejorar el carácter de los ciudadanos, a lo que apunta de manera efectiva es a la felicidad privada, pues se trata de un ideal de vida más próximo al de las ciudades helenísticas que al de las clásicas.

${ }^{37}$ LORD (1978: 354-357) sostiene que la forma de vida del mejor régimen está dedicada al disfrute ocioso de la música y de las artes antes que a las especulaciones. En este sentido, asegura que el empleo de philosophía en Pol. VII 15 remite a un sentido laxo del término, que se corresponde a lo que actualmente se denomina "cultura intelectual" y aclara: "Philosophy in the broad sense does not necessarily exclude theoretical speculation, but its core is traditional culture; and traditional culture means above all literary culture. The core of that 'philosophy' which is politically relevant is, in the language of Aristotle and his contemporaries, 'music' [el destacado es mío]". Los gobernantes de dicho régimen no son filósofos, sino caballeros que representan el ideal de la kalokagathía y que dedican su ocio a la admiración de lo que es bello e inútil en las obras de arte y en la poesía (EN 1125a11-12; Pol. 1338a37-b4). Este énfasis en el carácter musical de la educación es la antítesis de la tradición.

${ }^{38}$ DEPEW (1991: 349) advierte que aunque resulta tentador entender a partir de este pasaje que la contemplación es la actividad exclusiva o dominante del mejor régimen, a la que las demás actividades se subordinan como medios, solo afirma que si el concepto de acción es propiamente comprendido, la contemplación será vista como teniendo un carácter más activo que las actividades instrumentales. Ibíd., p. 351. Al reconocer que es la forma más paradigmática de actividad, el Estagirita hace de ella el principio ordenador y el más alto de los bienes gracias a la cual, se pueden alcanzar los demás bienes intrínsecos, que incluyen los actos excelentes en la esfera moral y política. En definitiva, a través de esta versión fuerte del inclusivismo, lo que DEPEW postula es que el bien político y la actividad contemplativa se apoyan y se vinculan mutuamente como condiciones de una aristocracia ideal. Ibíd., p. 361. De ahí que, como 
Gastaldi (2003) 39 , o como en el caso de BerTelli (2004), quien directamente afirma que ella no forma parte de ese proyecto político. Como vimos, en el preámbulo ético Aristóteles se limita a señalar la superioridad de la acción no instrumental, lo cual no implica que ella sea la actividad exclusiva del régimen ideal. Las concisas alusiones del pasaje de Pol. VII 3 no permiten inferir con certeza qué actividades comprende el bios praktikós como bios hairetótatos. En consecuencia, parecería que solo a partir de la consideración del diseño efectivo del mejor régimen podemos intentar aclarar cuál es el ideal de vida que Aristóteles defiende allí.

\section{La mejor forma de vida en la pólis ideal (Pol. VII 13-15)}

En los capítulos que siguen al proemio ético de Pol. VII 1-3, el Estagirita analiza las condiciones necesarias para la constitución del mejor régimen atendiendo a sus aspectos estructurales (tamaño y población en Pol. VII 4), geográficos (territorio y acceso al mar en Pol. VII 5 y 6), sociales (el carácter de los habitantes en $\mathrm{Pol}$. VII 7, sus partes constitutivas en Pol. VII 8, la distribución de funciones en Pol. VII 9 y la división de los grupos sociales en Pol. VII 10) y estratégicos (emplazamiento y defensa en Pol. VII 11 y 12). Aun cuando en este bosquejo nos ofrece una visión general de la organización y la vida de los ciudadanos, ${ }^{40}$ los elementos más significativos para elucidar su ideal de vida los encontramos en Pol. VII 13 a 15, en donde retoma el tratamiento de la felicidad, reflexiona sobre los fines de la vida y sobre las virtudes del régimen adoptando una perspectiva — en cierto modo - distinta de la del prólogo, pues la argumentación no se inserta aquí en un contexto dialéctico sobre las formas de vida. ${ }^{41}$

hemos visto, sostenga que son dos las formas ideales de vida: la de la persona genuinamente política y la del intelectual políticamente abierto. El autor sostiene que la palabra "filosofía" implica para Aristóteles un ascenso desde la práctica musical al conocimiento práctico y a la contemplación. Ibíd., p. 371. Véase, supra, n. 23.

${ }^{39}$ Respecto de la función de la theoría en el régimen ideal, GASTALDI (2003: 175) sostiene que ningún papel efectivo le es reconocido, ya que el bíos hairetótatos es práctico-político. A pesar de las numerosas interpretaciones a las que esta falta de reconocimiento ha dado lugar, para la autora ninguna resulta satisfactoria. En la Política esta cuestión está llena de lagunas, no se le otorga ninguna función al filósofo y su presencia no resulta homogénea respecto de la comunidad. Incluso en $E N \mathrm{X}$, donde su figura alcanza su máxima consagración y el ámbito de la práxis es degradado, la tensión entre ésta y la práxis permanece irresuelta. Ibíd., p. 184.

${ }^{40}$ La organización política, económica y social de los ciudadanos del mejor régimen que Aristóteles detalla en estos capítulos revela la naturaleza pacífica del mismo y, sobre todo, pone de manifiesto la inexorable participación política de todos los ciudadanos.

${ }_{41}$ Teniendo en cuenta la diferencia argumentativa y contextual que existe con el prólogo, no podemos pretender encontrar en este núcleo de capítulos, i.e. Pol. VII 13-15, una respuesta 
Aristóteles establece en estos tres capítulos los principios que debe tener en cuenta el legislador, los cuales constituyen el fundamento teórico del programa educativo, que comienza a desarrollar en los dos capítulos siguientes ( $P o l$. VII 16-17) y al que dedica enteramente el último libro (Pol. VIII).

Luego de reiterar en Pol. VII 13 (1332a8) la idea de que la eudaimonía es el fin del mejor régimen y definirla como actualización y uso perfecto de la virtud, en Pol. VII 14 propone la alternancia entre gobernantes y gobernados ( $\mathrm{Pol}$. 1332b25-27). Apoyándose en la identidad de la virtud de ambos con la del hombre mejor, asegura que es el legislador (ho nomothétes) quien debe ocuparse de estudiar cómo los hombres se convierten en buenos, por medio de qué formas de vida y cuál es el fin de la vida mejor (Pol. 1333a14-16). Significativamente, en este punto introduce la división del alma (Pol. 1333a 16-27), a la que no hace alusión en el prólogo y, por medio de la cual, distingue no solo la parte que tiene razón de la que no la tiene pero es capaz de obedecer a aquella, sino que también divide a la primera en práctica y teórica. ${ }^{42} \mathrm{~A}$ continuación, traslada esta distinción a la vida, específicamente, a la relación entre las actividades que son fines como el ocio, la paz y las acciones nobles - y los medios que permiten alcanzarlas - el trabajo, la guerra y las acciones necesarias, respectivamente- (Pol. 1333a30ss.). De sus reflexiones sobre los fines no solo se desprende la superioridad de la parte racional del alma, sino también la supremacía de la razón teórica sobre la práctica: "pues siempre para cada uno, lo más deseable es lo más alto que puede alcanzarse" (Pol.1333a30). ${ }^{43}$ Aristóteles deja en claro aquí la correspondencia que existe entre estas dos distinciones, i.e. la división del alma y sus acciones y la de los fines y medios de la vida, y, en ambos casos, enfatiza la superioridad de uno de sus términos: lo racional sobre lo que no posee razón, la

taxativa al problema de los bíoi inicialmente planteado. A pesar de estas diferencias, el cuerpo de Pol. VII-VIII es — como advierte DePEW (1991: 371) — una aplicación directa de los principios establecidos en los tres capítulos del proemio.

${ }_{42}$ Aristóteles pareciera presentar aquí una versión resumida de la división del alma, tal como puede observarse al contrastarla con el esquema propuesto en EN I 13 (1102b28-1103a10) y VI 1 (1139a3-17). En $D A 433 a 33$ no apela a esta división.

43 "Y con respecto a sus acciones, diremos que ocurre $<$ algo $>$ análogo (análogon), aquellas que corresponden a la parte que es mejor por naturaleza deben ser preferidas por los que pueden llevar a cabo o bien todas o bien las correspondientes a las dos (toîn duoîn); pues siempre para cada uno, lo más elegible (hairetótaton) es lo más alto que puede alcanzarse (akrótatou)." Pol. 1333a 27-30. Aristóteles no especifica cuáles son las dos partes del alma a las que alude en la disyunción, pues se limita a emplear el dual. La mayoría de los intérpretes entiende que se refiere a las dos inferiores. Por el contrario, BerTelli (2004: 197 n.2) entiende que alude a la dupla de la razón teórica y de la razón práctica, es decir, a las dos formas superiores, puesto que - a su entender - no tendría sentido el empleo del dual. Sin embargo, la argumentación del pasaje abona la interpretación mayoritaria, pues si un hombre que naturalmente no ha sido dotado para la contemplación no es capaz de realizar todas las acciones, al menos será capaz de realizar aquellas que corresponden a las dos partes inferiores del alma. 
razón teórica respecto de la práctica, los fines de la vida en relación con sus medios; y ello resulta manifiesto sin la necesidad de recurrir a sus otros tratados ético-políticos (pace BERTELLI y KRAUT). ${ }^{44}$ Esta jerarquía determina la organización del régimen político ideal (1333a37-39), los principios de la educación (Pol. 1333a 37-b5) y, en general, la elección de la forma de vida (1333a40-41).

Las consideraciones sobre los fines y medios de la vida permiten concluir que se trata de un régimen pacífico que apunta al ocio y a las acciones nobles. Sin embargo, el Estagirita no dice de manera expresa cuál es la actividad más alta. No obstante, el indicio más firme que abona una comprensión fuerte de un ideal de vida filosófico está dado por la supremacía de la razón teórica que se desprende de sus afirmaciones en Pol. 1333a26-30, la cual permite inferir que la filosofía en sentido estricto constituye dicha actividad..$^{45}$ De hecho, en Pol. VII 15 (1334a23-25) asevera que la filosofía es la virtud específica para el ejercicio del ocio (philosophías dè pròs tèn scholén), si bien reconoce que otras — como la moderación (sophrosúnes) y la justicia (dikaiosúnes) — también son necesarias para ese momento (Pol. 1334a32). De igual modo, puede argüirse que la alusión a la imagen mítico-poética de la Isla de los Bienaventurados (en makáron nésois, Pol. 1333a31) también abona esta lectura, pues recordemos que Platón le reconoce a los filósofos un lugar privilegiado en ellas. ${ }^{46}$ Asimismo, Aristóteles parecería confirmar esta interpretación

\footnotetext{
${ }^{44}$ Resulta difícil aceptar la interpretación de BERTELLI (2004: 197), quien elimina la división de la razón en teórica y práctica por no considerarla homóloga a las restantes distinciones. A su juicio, no hay ningún signo explícito que subordine una a la otra. En este sentido, afirma que quienes infieren a partir de esta división, que Aristóteles prefiere la razón teórica leen el pasaje con los ojos del Protréptico o de la EN. Ibíd., p. 198. Por su parte, KRAUT (1997: 138-139) asegura que Aristóteles solo afirma aquí que la combinación de las dos partes superiores del alma es mejor que la inferior, pero a partir de lo dicho en otras obras, queda en claro que considera superior a la razón teórica.

${ }^{45}$ Si bien es cierto que a partir de la descripción de los fines de la vida no es posible precisar si Aristóteles está pensando en la filosofía como fin último del mejor régimen, cuando afirma que "el político deberá legislar mirando todas estas cosas, tanto las partes del alma cuanto a sus acciones, pero mirando sobre todo las cosas mejores y los fines (mâllon dè pròs tà beltío kaì tà téle ) [el destacado es mío]" (Pol. 1333a37-39), parece aludir a actividad/es y fin/es que trascienden los ya enunciados, i.e. ocio, paz y acciones nobles, lo cual ratifica al aplicar este mismo criterio a la elección de las formas de vida y a las acciones (Pol. 1334a40-41).

${ }^{46} \mathrm{La}$ imagen mítico-religiosa de la Isla de los Bienaventurados - que aparece atestiguada por primera vez hacia el 700 a.C., más precisamente, en Hesíodo (Los trabajos y los días 168173) — designaba el ámbito divino del Más Allá y, geográficamente, se la identificaba con el extremo occidental de la Europa por entonces conocida. Con el transcurso de los siglos su empleo se generalizó incluyendo no solo a dioses y héroes, sino también a los hombres virtuosos adquiriendo así una connotación moral vinculada a las creencias órfico-pitagóricas sobre la inmortalidad del alma. Entre los distintos empleos atestiguados en la literatura arcaica y clásica que aluden a estas islas, el que hace Platón en el Gorgias 526c es en donde más claramente se las identifica como destino final de quienes han llevado una vida filosófica: "Alguna vez, al
} 
cuando asegura que la razón y el intelecto son para los hombres el fin de la naturaleza (ho dè lógos hemîn kaì ho noûs tês phúseos télos, Pol. 1334b15). En efecto, hacia el final del capítulo (Pol. 1334b12-28) retoma la distinción entre las partes del alma y aun cuando se limita a diferenciar la racional de la irracional sin hacer alusión alguna a la división homóloga entre la razón práctica y la teórica, es clara la superioridad que le reconoce al intelecto (nôis) como estado del alma (héxis, 1334b19) y como fin — conceptual y cronológicamenteúltimo de la existencia. No obstante, muchos intérpretes aseguran que el término philosophía no es empleado en Pol. VII 15 en un sentido técnico y lo identifican con un ideal cultural más amplio que incluiría las distintas actividades ociosas, principalmente, la música, ${ }^{47}$ si bien hay quienes lo interpretan de manera estricta. ${ }^{48}$ En consecuencia, tampoco existe acuerdo sobre el que pare-

ver un alma que ha vivido piadosamente y sin salirse de la verdad, alma de un particular o de otro cualquiera, pero, especialmente [...] de un filósofo que se ha dedicado a su ocupación, sin inmiscuirse en negocios ajenos mientras vivió, se admira y la envía a la Islas de los Bienaventurados" [La traducción es de CALONGE RuIZ (1992)]. En este mismo sentido, también resultan relevantes los pasajes de República 519b-c y 540 a-c. Sobre la génesis y la evolución del empleo de este mito en la literatura griega arcaica y clásica, cfr. MARTínez (1999).

${ }^{47}$ Como anticipamos, LoRD (1978: 354-355) asegura que Aristóteles habla aquí de filosofía en un sentido laxo y que si bien el término no necesariamente excluye la especulación teórica, su núcleo es la cultura tradicional que, por entonces, era la música. Véase, supra, n. 37. En una postura más extrema, BERTELLI (2004: 198) sostiene que a pesar de la embarazosa ("embarazzante") presencia de una virtud llamada 'filosofía' como actividad característica de la scholé, no es lícito atribuir a Aristóteles la intención de proponer en su ciudad ideal la vida contemplativa como télos, pues el ejercicio contemporáneo de las distintas virtudes, esto es: filosofía, moderación y justicia, aleja al ciudadano de la figura del sabio de $E N \mathrm{X} 8$, para quien estos bienes resultan un obstáculo para la teoría pura. El autor concluye que la philosophía que practican los ciudadanos virtuosos en los tiempos de ocio "non ha nulla a che fare con la vita contemplativa di en X 7", sino que se trata de actividades intelectuales y físicas al alcance de todos, muy emparentadas al ideal cultural de Tucídides. Véase, supra, n. 35. Por su parte, KRAUT $(1997:$ 143, 140) asegura que aunque de este empleo podría inferirse que la contemplación es el fin último para cada ciudadano y para la ciudad en su conjunto, Aristóteles lo utiliza tan ampliamente que no solo designa la comprensión filosófica de la causa primera del universo, sino también los estados intelectuales que se aproximan a esta condición como la música y quizás la astronomía, la geometría, etc. Por esta razón, concluye: "If Ar.'s citizens receive this kind of general intellectual training, they have studied 'philosophy' in the broad sense." GASTALDI (2003: 176) suscribe a la interpretación amplia de philosophía al afirmar que se trata de un término genérico destinado a referir a una multiplicidad de actividades culturales, pero no filosóficas.

${ }^{48}$ Por el contrario, Lisi (2004b: 115 n.1) sostiene que 'filosofía' es aquí sinónimo de sophía, ya que el Estagirita refiere a ella como virtud de la parte intelectual del alma y no como actividad. A su juicio, resulta poco probable que Aristóteles pensara en el concepto "actividades culturales", que es una noción moderna. Además, tampoco cree que aludiera a los espectáculos teatrales, simposios y actividades deportivas, pues estos estaban destinados a educar la parte inferior del alma. Según Lisi, las apariciones del término 'filosofía' a lo largo de la Política responden a un sentido técnico específico. Desde otra perspectiva, DePEW (1991: 371) entiende que en este contexto Aristóteles emplea philosophía en un sentido específico designando un ascenso desde la práctica musical a la sabiduría práctica y a la contemplación "[...] by which rationa- 
ciera ser el indicio más claro sobre el contenido de la vida práctico-contemplativa. Aunque no es posible determinar con exactitud la amplitud semántica con la que el Estagirita emplea el término en este caso, difícilmente podría estar ausente el significado técnico que este adquirió a partir de la obra de su maestro. ${ }^{49}$ Aun cuando no resuelve la cuestión, podemos señalar que ambas acepciones están, de algún modo, presentes aquí, ya que la filosofía como disciplina supone un interés general por la cultura, i.e. philo-sophía. De modo que la filosofía en sentido estricto no solo no estaría excluida de las actividades ociosas del régimen ideal, sino que sería el fin al que todos los ciudadanos apuntan, incluso la gran mayoría que no pueden dedicarse a ella (con CoOPER 2012 y 2010). En definitiva, respecto del mejor régimen podemos legítimamente afirmar que se trata de una ciudad filosófica en sentido amplio, cuyo fin último es la filosofía de manera estricta (pace BERTELLI 2004).

Teniendo en cuenta las dificultades textuales que presentan los capítulos del proemio y, en general, los problemas de redacción que se perciben en el libro séptimo, pero, sobre todo, el carácter inconcluso del último libro de la Política no es posible saber si Aristóteles se refería específicamente a la educación filosófica de aquellos que naturalmente han sido dotados para la contemplación. Aunque nada podamos decir al respecto, los fundamentos teóricos que expone en estos dos últimos libros sugieren la relevancia de la filosofía en el proyecto político que allí diseña (con Lisi 2004). ${ }^{50}$ Las consideraciones sobre los fines de la educación musical expuestas en Pol. VIII revelan que a diferencia de las otras disciplinas, la importancia pedagógica de la música reside en el hecho de que se trata de una actividad no instrumental (Pol. VIII 3 1338a11-32). Más allá de sus distintas funciones (educación, juego y ocio, Pol. 1339b13-15), su propósito último no es otro que el de escuchar bellas melodías y ritmos (Pol. 1341a14) y, en el caso subsidiario del dibujo, contemplar la belleza de los cuerpos (Pol. 1338b1-2). En tal sentido, podría decirse que dichas actividades

lity, which marks the exercise of virtues and so happiness, is developed and intensified in increasingly profound ways." Según el autor, esta concepción de la contemplación como emergente de y continua con las actividades ociosas musicales acuerda plenamente con los principios establecidos en Pol. VII 1-3.

${ }^{49}$ Sobre el significado no filosófico de la palabra philosophía en el siglo V a. C. y el sentido específico que adquiere a partir de Platón, cfr. HADOT (1998: 26-34; 52-64).

${ }^{50}$ Respecto de esta cuestión, acuerdo con Lisi (2004: 115 n.1) en que "[...] el estado fragmentario de la Política impide saber si no se avanzaba en el tema de la educación filosófica de una parte de la población. Es verdad que no puede avanzarse, por tanto, nada sobre el contenido concreto de la educación 'filosófica', [...] pero no es menos cierto que una posición extremadamente escéptica sobre su contenido debe basarse en la negación de los principios de la psicología aristotélica expresados en los libros VII y VIII y de toda la ética [...] [el destacado es mío]." Sobre la ausencia de un lugar específico para la filosofía en el programa educativo ideal y las interpretaciones a las que ha dado lugar, cfr. GASTALDI (2003: 176-178). 
estarían próximas a — incluso serían de la misma clase que ${ }^{51}$ - la práxis no instrumental a la que Aristóteles alude en el pasaje de Pol. VII 3 (1325b16-23). La superioridad que le atribuye al pensamiento y a la contemplación ( $\mathrm{Pol}$. 1325b19-23), la analogía con la divinidad y el orden cósmico como modelos de la acción para sí (Pol. 1325b28-30), la división del alma y el reconocimiento de la supremacía de la razón teórica en Pol. VII 14, y la afirmación de la filosofía como virtud propia del ocio en Pol. VII 15 sugieren que estas actividades no constituyen la forma más elevada de práxis y que el ideal de vida en el mejor régimen es el contemplativo, lo cual no implica la exclusión de otras actividades ni tampoco supone negar el carácter político que la vida del sabio - como la de cualquier otro ciudadano - necesariamente conlleva. También es cierto que todos los indicios que Aristóteles ofrece en favor de una interpretación estrictamente filosófica del bios hairetótatos son, en algún punto, ambiguos, lo cual pone de manifiesto su indefinición en el tratamiento general de esta cuestión..$^{52}$ Uno de los principales obstáculos que impiden identificar la actividad contemplativa como fin último del régimen ideal reside en el hecho de que en el esquema de distribución de funciones que presenta en Pol. VII 9 no alude en ningún momento a la figura del filósofo. En efecto, las funciones políticas se limitan a la militar y a la deliberativa, y el ejercicio alternado de ambas es determinado por la edad. Solo la función sacerdotal, cuya práctica restringe a quienes se han retirado podría ser análoga a la actividad filosófica y permitiría resolver la relación de ambos bíoi en el régimen ideal. Tal es la interpretación propuesta por IRWIN (1990: 81) y aunque es admisible, Aristóteles no la presenta como la solución a este problema. ${ }^{53}$ También hay quienes sostienen que el Estagirita no alude al lugar que ocupan los filósofos en el régimen, porque se trata de una minoría excepcional (BROWN 2009: 491), cuya educación y acciones no constituyen el fin de la comunidad (KRAUT 1997: 139), por lo cual no amerita consideración en la esfera política (GASTALDI 2003:179). Las indicaciones tácitas y expresas que ofrece a lo largo de ambos libros no parecen dar apoyo a esta lectura, pero incluso si ella fuera aceptada, el grupo minoritario de los filósofos no estaría exento del ejercicio de las funciones cívicas que competen a todos los ciudadanos.

\footnotetext{
${ }^{51}$ Tal es la interpretación que, como vimos, propone DEPEW (1991), quien establece una continuidad ascendente entre música y contemplación. Véase, supra, nota 48. Para una crítica a esta lectura, cfr. GASTALDI (2003: 178 n.55).

52 Para Gastaldi (2003:177), los indicios que hemos analizado aquí son débiles y, sobre todo, genéricos y se trata de un problema irresuelto en la propia obra de Aristóteles. Véase, supra, nota 39 .

${ }^{53}$ Véase, supra, nota 29.
} 


\section{La función política de los filósofos (Pol. VIII y EN X 9)}

Hacia el final de la Política, Aristóteles hace algunas afirmaciones que resultan significativas para entender el lugar que los filósofos ocupan en el régimen. Así por ejemplo, respecto del carácter ético de las melodías y armonías que deben intervenir en la educación asegura que además del dorio "es preciso admitir también cualquier otro que nos aprueben los que participan del estudio de la filosofía y la educación musical" (hoi koinonoì tês en philosophíai diatribêes kaì tếs perì tèn mousikèn paideías, Pol. 1342a31-32), ${ }^{54}$ de lo cual es posible inferir que estos intervienen en la elaboración de las pautas educativas que competen a esta disciplina. De igual modo, en otro pasaje menciona a los músicos actuales y a los filósofos que tienen experiencia en la educación musical (Pol. 1341b27-31), asignándoles el estudio preciso de estas cuestiones, a las cuales Aristóteles se limita a presentar de manera esquemática. En Pol. 1341 b33 recurre a la división de las melodías propuesta por algunos filósofos. En dos ocasiones critica las armonías que $<$ el personaje de $>$ Sócrates admite en la República (Pol. 1342a33; 1342b23-24). Estas referencias ponen de manifiesto y nos plantean varias cuestiones. En primer lugar, revelan que los filósofos en general y, en particular, aquellos experimentados en la música no solo forman parte del mejor régimen, sino que intervienen en su conformación, pues su papel consiste en establecer normas más o menos universales. Ahora bien, con vistas a comprender su vínculo efectivo con el poder, cabe preguntarse si estas prescripciones las hacen cumpliendo una función directiva y/o legislativa o meramente cívica en dicho régimen o si, por el contrario, las hacen previo a su constitución, por lo cual estarían al mismo nivel que las que el propio Aristóteles realiza en los dos últimos libros de la Pol. En el primer caso, su intervención tendría un carácter estrictamente político, mientras que en el segundo podríamos describirlo como meta-político. El argumento y las referencias tácitas sugieren la segunda interpretación, pues son los filósofos - como Platón y Aristóteles - quienes conciben y bosquejan Estados ideales, pero la actividad legislativa que - como vimos - estos desempeñan en el mejor régimen requiere también experiencia política (ENX 9 1181a11-12), lo cual abona la primera lectura. Aun cuando parece posible aceptar ambas interpretaciones sin caer en contradicción, lo cierto es que ya sea como miembro del régimen ideal o como su creador, la función del filósofo es nomotética, pues tal como lo demuestran las propias reflexiones de Aristóteles en Pol. VII-VIII y en EN X: a quién otro sino al filósofo corresponde la tarea de establecer cómo y a través

\footnotetext{
${ }^{54}$ El destacado es mío.
} 
de qué formas de vida o costumbres (epitedeumáton) los hombres se convierten en buenos ${ }^{55}$ y cuál es el fin de la vida mejor (Pol. 1333a14-16).

Aristóteles responde, de algún modo, a las dos primeras preguntas referidas a la función del legislador en el capítulo final de la $E N$, donde plantea el problema de hacer efectivo el conocimiento práctico del que se ha ocupado a lo largo de obra (EN 1179a33-b4) ${ }^{56}$ A pesar de la complejidad de $E N$ X 9, el Estagirita deja en claro que la ley es el principal instrumento para concretar ese saber, pues es expresión (lógos) de cierto saber práctico y del intelecto (tinos phronéseós kaì nô̂, EN 1180a22) y gracias a la necesidad (anagkastikèn, 1180a21) que impone, cumple un papel fundamental en la educación, las costumbres y, en general, para toda la vida (EN 1180a4). Ello explica la importancia que le otorga a la figura del nomo-thétes, cuyo propósito es hacer buenos a los hombres por medio de las leyes (EN 1180b24-25). No obstante, destaca su peculiaridad al señalar la inevitable tensión entre el carácter general de la ley y la individualidad de su aplicación, al cuestionar cómo y dónde es posible convertirse en legislador y, en definitiva, al no definir quién ha de desempeñar la función correspondiente. Más allá de su carácter singular, reconoce que se trata de una actividad política, pues afirma que las leyes son la obra propia (érgois, EN 1181a23) de esta disciplina y que el legislador no solo debe haber sido educado y habituado en ellas, sino también tener experiencia (EN 1181b112). Como bien señala GASTALDi (2003:185), Aristóteles es muy elíptico respecto de la relación entre el filósofo y el político. Si bien es cierto que su silencio es muy significativo, no es posible identificar al legislador con un filósofo de la política, quien estaría al mismo tiempo fuera de la esfera de mando y conectado con la ciudad, y que — según la autora - se diferenciaría del filósofo puro retirado de la ciudad. Por el contrario, entiendo que el legislador, el filósofo y, en general, todo ciudadano de la pólis ideal nunca pueden retirarse de la ciudad, pues desde antes de su nacimiento e incluso de su concepción son educados en las leyes de la ciudad y habituados conforme a ellas (Pol. VII 1617). En este sentido, tampoco parece correcto distinguir entre el filósofo dedicado a la política y el puro, no solo porque Aristóteles no propone esta distinción en ninguna de las dos obras, sino, sobre todo, porque el filósofo en cualquiera de sus variantes - es, ante todo, un ciudadano y como tal no está

${ }^{55}$ Pol. VII 2 1325a7-10.

${ }^{56}$ Como asegura Cooper (2012: 73-74), el capítulo final de la $E N$ es clave para entender el carácter fundamentalmente político de la ética. Allí, Aristóteles subraya la singularidad del conocimiento práctico entre todas las formas de conocimiento humano y deja en claro que la eudaimonía solo puede lograrse en una comunidad política. También LISI (2004b: 118), a propósito de $E N X$ 9, sostiene que "[...] el contexto político es fundamental para el desarrollo de la verdadera felicidad de la parte inmortal del hombre. Sin él la contemplación no es posible." 
exento de ninguna de sus responsabilidades cívicas. En definitiva, estos pasajes del final de la Política muestran que los filósofos establecen las leyes (educativas) del régimen, por ende, cumplen una función legislativa. Aun cuando parece improbable que Aristóteles haya pretendido establecer una identidad plena entre el philósophos (al menos, tal como lo describe en EN X 7-8) y el nomothétes, sus afirmaciones sugieren que algunas de sus funciones coinciden.

\section{Conclusión}

Teniendo en cuenta las dificultades textuales e interpretativas antes mencionadas, no es posible establecer con precisión en qué consiste concretamente el bios praktikós de Pol. VII 3 ni, en términos más generales, precisar cuál es la vida mejor a la que Aristóteles apunta a través del mejor régimen. No obstante, hemos visto que los indicios que ofrece en Pol. VII-VIII sugieren que se trata de un modo de vida cuyo fin último es la theoría, pero que comprende también todas las actividades ético-políticas propias de un ciudadano virtuoso. Aunque resulte desalentador admitirlo tampoco es posible determinar con exactitud si los filósofos cumplen una función directiva en el régimen ideal, ni cuál es su relación efectiva con el poder más allá de la obligada alternancia en los cargos que atañe a todos los ciudadanos y de la indudable actividad legislativa que desempeñan, al menos, en la esfera educativa (pace COOPER 2012; ${ }^{57}$ BROWN 2009; ${ }^{58}$

\footnotetext{
${ }^{57}$ Según CoOper (2012: 138, 140-141), el filósofo contemplativo, cuyo conocimiento comporta la filosofía completa, i.e. práctica y teórica, posee en toda su medida el saber político y como el resto de los ciudadanos lleva una vida práctica, pero no se desempeña como un líder político. Aun cuando el autor señala que la vida contemplativa no se trata de la contemplación extasiada de las entidades divinas, advierte que la apasionada dedicación al pensamiento y la discusión teorética excluye la clase de compromiso político que caracteriza la segunda mejor vida. COOPER no detalla en qué textos sustenta la distinción que propone respecto de los distintos miembros que componen la comunidad política, a saber: filósofos, líderes políticos, virtuosos y los meramente decentes. De hecho, en un trabajo anterior, él mismo reconoce las limitaciones textuales de su interpretación, cfr. COOPER (2010: 249 n.46). Véase, supra, nota 25.

${ }^{58}$ BROWN (2009: 488, 491) sostiene que Platón y Aristóteles representan una de las tres formas antiguas de defensa del retiro de la política frente al predominio de la ideología de la acción, la cual persistió hasta la Antigüedad tardía. Según el autor, ambos aceptan los supuestos fundamentales de dicha ideología, pero sostienen que existen seres humanos excepcionales que pueden dedicarse a la contemplación, lo cual les permite trascender la naturaleza humana y elevarse hacia lo divino. Aunque los argumentos a los que Platón y Aristóteles apelan difieren, el autor sostiene que el carácter excepcional del ideal filosófico les permite evitar la tensión que esta cuestión genera en su pensamiento ético. Por mi parte, entiendo que dada la naturaleza intrínsecamente política que ambos filósofos le reconocen al hombre, en ninguno de los dos casos es apropiado hablar de un "retiro de la política", ni siquiera respecto de aquellos que se dedican a la contemplación. Aristóteles nunca olvida el carácter eminentemente político del hombre (pace BROwN 2008: 83).
} 
GASTALDI 2003; ${ }^{59}$ con Lisi $2004^{60}$ ). A pesar de las numerosas incertidumbres que plantea el estudio de esta cuestión, no es admisible la propuesta de eliminar a la filosofía en sentido estricto del proyecto político ideal, no solo porque sus fundamentos teóricos remiten a esta actividad como fin último, sino porque solo a partir de ella somos capaces de reflexionar sobre la mejor forma de vida en el mejor régimen político. ${ }^{61}$

\section{Bibliografía}

ACKrill, John L. (1975). "Aristotle on eudaimonia". Proceedings of the British Academy, LX, pp. 339-359.

Araujo, María; MARÍAs, Julián (1994). Aristóteles. Ética a Nicómaco, Edición bilingüe, introducción, traducción y notas. Madrid: Centro de Estudios Constitucionales.

BÉnatouïL, Thomas; Bonazzi, Mauro (eds.) (2012). Theoria, Praxis and the Contemplative Life after Plato and Aristotle. Leiden - Boston: Brill.

Bertelli, Lucio (2004). "L'elogio del bios praktikos in Politica VII di Aristotele". En: Lisi, Francisco (ed.). The ways of life in Classical Political Philosophy. Sank Augustin: Akademie-Verlag, pp. 179-200.

Brown, Eric (2011). "Aristotle on the Choice of Lives: Two Concepts of SelfSufficiency".

[PDF] $<$ http://www.artsci.wustl.edu/ eabrown/pdfs/BrownAutarkeia.pdf $>$ [Fecha de consulta: $12 / 2013]$

. (2009). "False Idles: The Politics of the Quiet Life". En: BALOt, Ryan K. (ed.) A Companion to Greek and Roman Political Thought. New York: Blackwell, pp. 485-500.

\footnotetext{
${ }^{59}$ Como vimos, GASTALDI (2003: 185) afirma que el filósofo puro se retira de la ciudad y el que se dedica a la política está, a la vez, fuera de la esfera de mando, pero conectado a la pólis en su condición de experto. Aunque la autora admite la dificultad de precisar esta relación, sugiere una sinergia entre ambos: "Difficile dire come questo rapporto si esplichi nella realtà, più facile mostrare come la collaborazione tra político e scienziato della política si realizzi in un' ariste politeia dove lo scenario pacificato prodotto dall'analisi teorica permette di pensare alla coesistenza di tutte le figure, ed anzi, come si è visto, impone la sinergia delle diverse competenze, teoriche e pratiche, proprio ai fini della realizzazione del modello [el destacado es mío]." Véase, supra, p. 11.

${ }^{60}$ Respecto de la relación del filósofo con la política, Lisi (2004b: 119) sostiene que a pesar de que el primero es fin de la comunidad, no es necesario que ocupe el poder político. No obstante, reconoce que: "De las palabras de Aristóteles no puede descartarse completamente que el filósofo ejerza el poder directamente, pero sí que debe hacerlo a través de las leyes o por su mediación, ya que la ley ofrece un marco aparentemente objetivo y es mejor aceptada por los hombres [el destacado es mío].” El autor sugiere así la vinculación y hasta la posible identificación del filósofo y del legislador.

${ }^{61}$ Para el presente trabajo he consultado la edición de Ross (1964), los comentarios de NeWman (1950), los de Kraut (1997) y las traducciones de RACKHAM (1944), García VAldés (1988), SANTA CRUZ y CRespo (2005) de la Pol. En el caso de la EN he trabajado con la edición de BYwATER (1962), el comentario de JOACHIM (1955), las traducciones de ARAUJO y MARÍAS (1994) y la de Ross (2009).
} 
. (2008). "Contemplative Withdrawal in the Hellenistic Age". Philosophical Studies, CXXXVII, 1, pp. 79-89.

BYwATER, Ingram (1962). Aristotelis Ethica Nicomachea. Oxford: Clarendon Press.

Calonge Ruiz, Julio et ál. (1992). Platón. Diálogos. Gorgias, introducción, traducción y notas. Madrid: Gredos.

CArTer, Lynn B. (1986). The Quiet Athenian. Oxford: Clarendon Press

Charles, David (1999). "Aristotle on well-being and intellectual contemplation". Aristotelian Society Supplementary Volume, LXXIII, 1, pp. 205-223.

Cooper, John M. (2012). Pursuits of Wisdom. Six Ways of Life in Ancient Philosophy from Socrates to Plotinus. Princeton-Oxford: Princeton University Press.

. (2010). "Political community and the highest good". En: LENNOX, James G. y Bolton, Robert (eds.). Being, Nature and Life in Aristotle. Essays in Honor of Allan Gotthelf. Cambridge: Cambridge University Press, pp. 212-264.

Demont, Paul (1990). La cité grecque archaïque et classique et l'idéal de tranquillité. Paris: Belles Lettres.

DePew, David J. (2009). "The Ethics of Aristotle's Politics". En: Balot, Ryan (ed.) A Companion to Greek and Roman Political Thought, New York: Blackwell, pp. 399-418.

. (1991). "Politics, Music and Contemplation in Aristotle's Ideal State". En: Keyt, David y Miller, Fred D. (eds.) A Companion to Aristotle's Politics, Oxford - Cambridge, Mass.: Blackwell, pp. 346-380.

Festugière, André-Jean (1950). Contemplation et vie contemplative selon Platon, Paris: J. Vrin.

García Valdés, Manuela (1988). Aristóteles. Politica. Introducción, traducción y notas. Madrid: Gredos.

GastAlDI, Silvia (2004). "Il dibattito sui generi di vita nel cap. 2 del libro VII della Politica di Aristotele", en: Lisi, Francisco (ed.), The ways of life in Classical Political Philosophy, Sank Augustin: Akademie-Verlag, pp. 167-179.

. (2003). Bios Hairetotatos. Generi di vita e felicita in Aristoteles, Napoli: Bibliopolis.

Gregorio, Francisco (2004). "Leo Strauss, Hannah Arendt. Deux versions de 1'aristotelisme politique aux XXe siècle", en: Lisi, Francisco (ed.) The ways of life in Classical Political Philosophy, Sank Augustin: Akademie-Verlag, pp. 231-250.

GuARIGlia, Osvaldo (1979). "Dominación y legitimación en la teoría política de Aristóteles", Revista Latinoamericana de Filosofía V-1, pp. 15-42.

Hadot, Pierre (1998). ¿Qué es la filosofía antigua? Traducción de Eliane Cazenave Tapie Isoard. México: Fondo de Cultura Económica.

Heinaman, Robert (1988). "Eudaimonia and self-suffiency in the Nicomachean Ethics", Phronesis, XXXIII, 1, pp. 31-53.

IRwIN, Thomas H. (1990). "The Good of Political Activity”. En: PATZIG, Günther (ed.) Aristoteles' "Politik". Acten des XI Symposyum Aristotelicum. Göttinguen: Vandenhoeck \& Ruprecht.

JAEGER, Werner W. (2011). "Sobre el origen y la evolución del ideal filosófico de la vida". En: Aristóteles: Bases para la historia de su historia de su desarrollo intelectual. Traducción de José GaOs. México: Fondo de Cultura Económica, pp. 467-515. 
JoAchim, Harold H. (1955). Aristotle. The Nicomachean Ethics: a Commentary. Oxford: Clarendon Press.

Kelsen, Hans (1977). "Aristotle and the Hellenic-Macedonian Policy". En: BARNES, Jonathan; SchofIEld, Malcom; SorABJi, Richard (eds.). Articles on Aristotle, Vol. 2: Ethics and Politics. London: Duckworth, pp. 170-194.

Kraut, Richard (1997). Aristotle. Politics. Books 7-8. Traducción y comentario. Oxford: Clarendon Press.

LISI, Francisco (2004a). "Ways of Life and Happiness in Classical Thought". En: . (ed.), The ways of Life in Classical Political Philosophy. Sank Augustin: Akademie-Verlag, pp. 11-31.

(2004b). "Vida teórica, vida práctica y felicidad en Aristóteles". En: . (ed.), The ways of Life in Classical Political Philosophy. Sank Augustin: Akademie-Verlag, pp. 95-120.

LorD, Carnes (1978). "Politics and Philosophy in Aristotle's Politics". Hermes, CVI, pp. 336-357.

MARTíneZ, Marcos (1999). "Las Islas de los Bienaventurados: Historia de un mito en la literatura griega arcaica y clásica”. CFG: egi 9, pp. 243-279.

Newman, William L. (1902). The Politics of Aristotle, with an Introduction, two prefatory essays and notes critical and explanatory, Vol. III. Oxford: Clarendon Press.

Rackham, Harris (1944). Aristotle. Politics. Cambridge, Mass.-London: William Heinemann.

Ross, William D. (2009). The Nicomachean Ethics. Introducción y notas de Leslie BROWN. Oxford: Oxford University Press. . (1964). Aristotelis Politica. Oxford: Clarendon Press.

Rowe, Ch. (2004). "The Best Life according to Aristotle (and Plato). A Reconsideration". En: Lisi, Francisco (ed.). The ways of Life in Classical Political Philosophy. Sank Augustin: Akademie-Verlag, pp. 121-133.

Santa Cruz, María I.; Crespo, María I. (2005). Aristóteles. Política. Introducción, traducción y notas. Buenos Aires: Losada.

Sсотт, Dominic (1999). "Aristotle on well-being and intellectual contemplation: Primary and secondary eudaimonia". Aristotelian Society Supplementary Volume, LXXIII, 1, pp. 225-242.

Solmsen, Friedrich (1964). "Leisure and play in Aristotle's Ideal State". Rheinisches Museum für Philologie, CVII, 3, pp. 193-220.

SuÑol, Viviana (2013). "La discusión aristotélica sobre los modos de vida. El contraste entre el bios theoretikós en Ética a Nicómaco X 7-8 y el bíos praktikós en Politica VII 3", Tópicos. Revista de Filosofia, 45, pp. 9-47.

Viviana SUÑOL

Consejo Nacional de Investigaciones Científicas y Técnicas (CONICET)

Instituto de Investigaciones en Humanidades y Ciencias Sociales de la Facultad de Humanidades y Ciencias de la Educación

Universidad Nacional de La Plata, Argentina

vsunyol@yahoo.com 